\title{
Research on Method to Determine the Business Function of Logistic Support Informational System for Equipment

\author{
JIN-xing,ZHANG-ruyi,GUO-xiao,ZENG-zhaoyang \\ CHINA AERO-POLYTHECNOLOGY ESTABLISHO, NO.7 JINGSHUN ROAD BEIJING 100028
}

Keywords: requirement of logistic support, WBS of logistic support, configure management of WBS, logistic support of informational system, logistic support

\begin{abstract}
To improve the development of informational support of equipment, constructed the logistic support informational system is one of the choice. In order to establish informational system which adapt to the requirement of equipment, how to confirm the business function of logistic support informational system is a difficult of each designer to overcome. In present, although, there have not the standard to confirm business function of information systems, but to select the suitable function in system is only way which must be passed. This research focus on the relationship between resources of logistic support to equipment and each specific work in logistic support with WBS, and aid with method of configuration management to determine the informational system, and provide an example of equipment informational support system to build up the business function with its customized feature.
\end{abstract}

\section{Introduction}

Informational support is the development trend of equipment logistic domain, with the development of information technology, the attention of equipment logistic support focus on the information which could reflect the condition and requirement of support[1-2]. In order to achieve the informational support, in the field of integrated support equipment have been researched many years and formed many mature information technology products, informational systems of logistic support that is one of the representatives[3-4].

Informational systems in logistic support of equipment is one of the method to practice the logistic support in informational. By the aid of information system, crews of aircraft could keep clear all requires from all equipment and arrange all kinds of resource to fulfill them. Additional, informational system could aid crew to decide what time to do what work and with how to do it. With several years in exploration and practice, in the field of informational system, there have been reached a consensus on the information systems that three feathers are necessary which are architectural design, mathematical model and information technology. However, almost all of the system focus the eyes on the information technology, but pay a few attentions on the architectural design such as business function setting [5-7]. For example, since there have not standard in business function setting for the requirement in the specific features of the equipment that made each individual system involves their own perfect function but confused the entirety functional arrangement while projecting system function.

In order to establish functional setting of informational system, the most important is to make clear the requirement of the equipment in logistics support, and then on the base of analysis the resources requirement, established the relationship between the logistic requirement and resource in logistic. Secondly, at the aid with the WBS to disassemble the requirement to each individual and special works [8-10]. The last but not least is to manage the configuration of each special work to set up the informational base to build the system [11-14]. Finally, established a method to set up the informational systems functional which keeps individual features with each type of equipment services. Above all, the shortage of present in confirms the support information system and follow the entirety arrangement has been overcome. 


\section{Backgrounds}

\subsection{Requirement of Maintenance}

Keep clear requirement to equipment is prerequisite for the work while establish the informational system, although the concept of equipment covers a broad range from large, complex systems to single appliance and then make a complex and tremendous requirement in logistic, but all equipment have one common aspect that is requirement of the same support resources, that is, workload of support, complex degree of support, time limit, equipment and tools, facilities and space, material and spare parts, reason of work and so on. Although the different equipment require the different resources, but by research the different types of equipment dependent on all kinds of support resources, and that combing correspondence with specific work, which could establish a clear distinguish between each equipment.

For example, the special work of one type of transport are: making planning and publishing the maintenance order, check while flights, check and inspection, isolated failure, fuel and refuel, removal and install spare parts, and all of this keep the relationship with the support resource as follow(fig1).

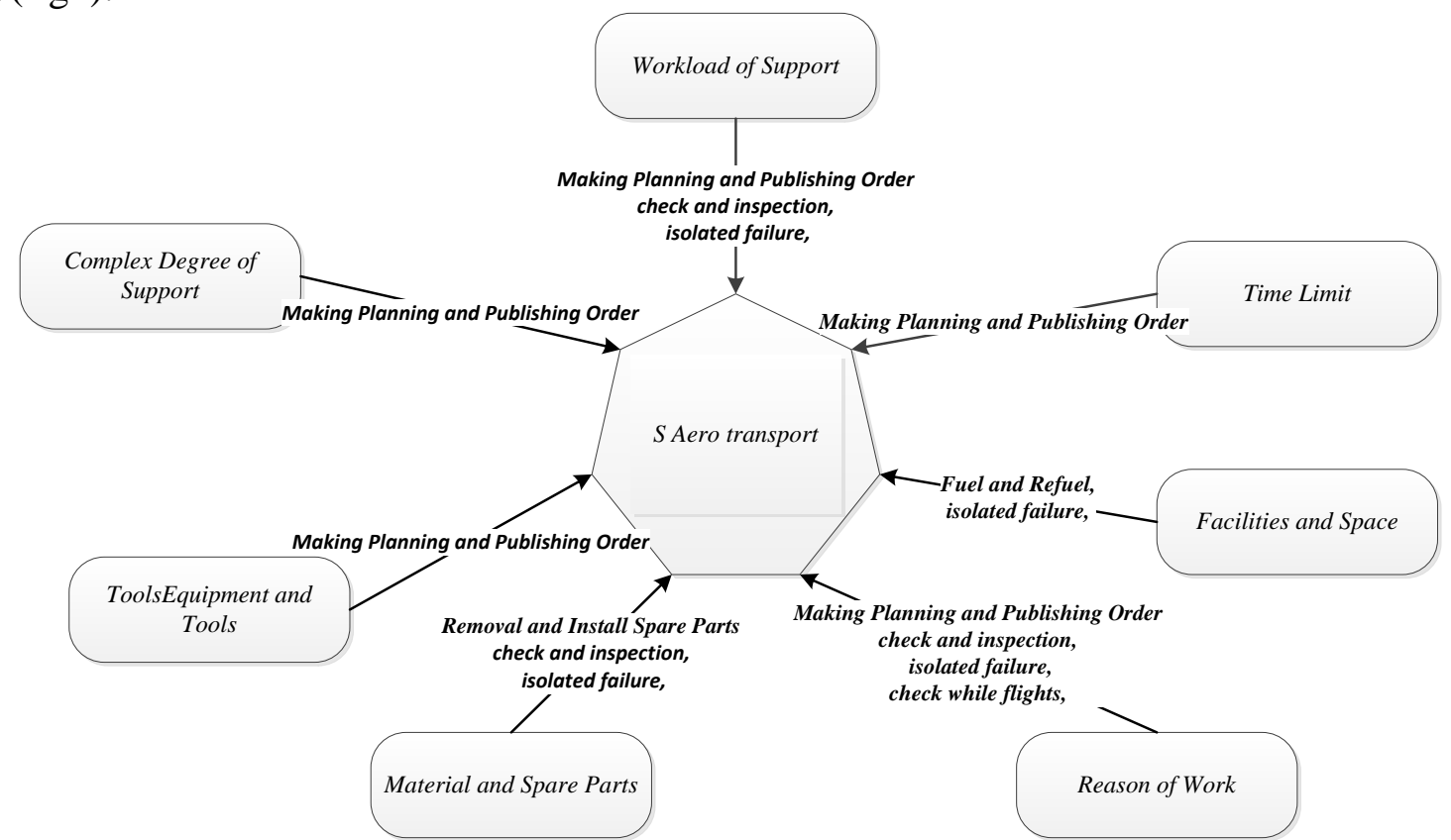

Fig 1 Relationship between Logistic Support Source and Maintenance Requirement

\subsection{Informational System}

Informational system is one of the practice methods for information logistic supports which could manage all kinds of logistics support information as the basic function such as add/deleted/edit/search. Furthermore, informational system could assist crew of aircraft to formulate repair plan and arrange maintenance resources on the base of analysis the logistics support information. Additional, informational system could also exchange date of equipment with other system, such as training system or human resource system, through interface which had been arrange early.

On the background of the informational support for equipment, informational system could improve the effective and reduce the workload of aircraft crew by means of execute repeating and programming task of informational system. In nature, the system manages logistics information which fulfilled by hand in traditional. At the same time, informational system could also provided maintenance advice on when and why to replaced spare part of which aircraft by analysis all kinds of information which came from logistics and other system. Above all, informational system could aid crews to establish a balance between security degree and support costs of aircraft that realize the perfect effective of maintenance.

\subsection{WBS-ILS}

As the classical file of WBS said, <Guide of Knowledge to Item Management System>, the 
target of WBS is everything which could achieve the purposes by disassembles the ending target to many parts and many level in each parts to the terms. There are three method in WBS, the first is disassemble the ending target which called starting from the boot, the second is to assemble the each work to the ending target which called starting from the ending, and the third is copied work structure from other item which likely this one. In this research, establish WBS-ILS, which is WBS of integrated logistics support. On this method, WBS-ILS is starting from boot, which is dissemble the total logistics support of equipment to lots of items, then disassemble each item to a group of special work and builds up the structure of WBS-ILS(fig 2).

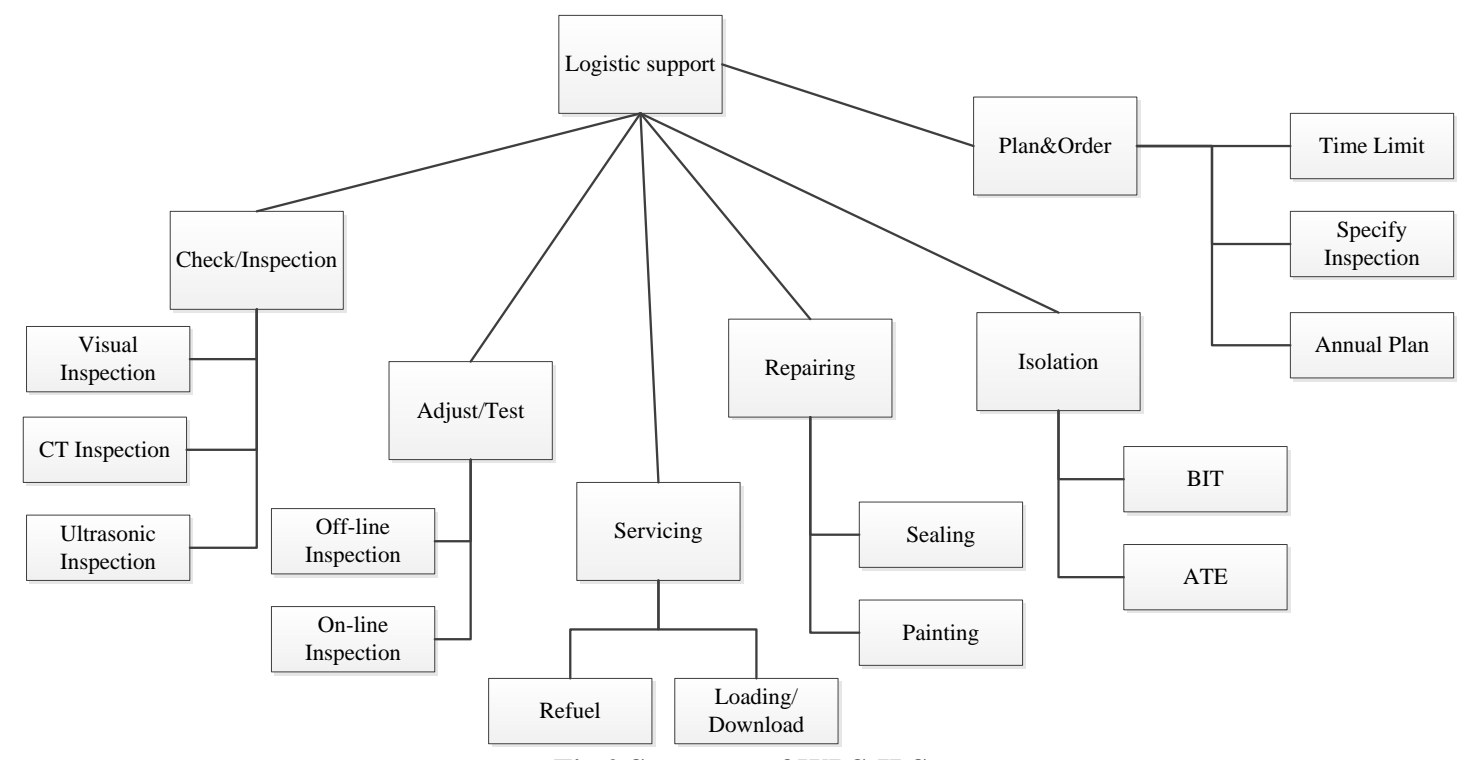

Fig 2 Structure of WBS-ILS

Set up $\mathrm{G}$ as the structure of WBS, $G=\{V, E\}$

$V=\left\{V_{1}, V_{2}, \ldots V_{n}\right\}$ means all special work assemble.

$E=\left\{V_{i}, V_{j}\right\}$ means the relationship between each special work, as all of the special work keep the feather of atomic, then $(i \neq j)$

By means of logistics WBS, the special work of maintenance could keep clear and provided proof to establish informational system with the feather of individual requirement which is suitable for one kind of special equipment. WBS of logistic disassemble total maintenance work as the boot and set each special work as the top and ensure that each top keep the feather of atomic.

\subsection{Confirm Major Operation of Informational System}

With the differences for the required of each types of aircraft, although the informational systems could confirm business function by made-by-order mode, but which would enlarge the cycle and workload cost while establish the system. In additional, this mode also set difficult while arrange interface. All of above does not follow the rules in informational system which called generated at one time and use at multiple times. To solve the problem, put the system based on WBS logistics is an effective solution.

\section{Configure Management of ILS-WBS}

\subsection{Purpose}

The purpose of configuration management for WBS-ILS is to regulate function and physical characteristics during design the informational system, that keep the system suit to the requirement of special equipment. Since the capabilities of equipment informational system research needs to be based WBS to, and therefore WBS configuration management enable it to better achieve the informational system, reduce the complexity of the business function set, shorten the cycle in design, while enhancing usefulness of the information system security. 


\subsection{Configure Management}

\subsubsection{Identify}

$G^{I L S-W B S}=I D^{I L S}+\operatorname{Re} v^{I L S}+n a m e^{I L S}, I D^{I L S}$ is the unique identification of WBS, $\operatorname{Re} v^{I L S}$ is the number of version, name $^{I L S}$ is the special work which called top nods

WBS identifies is the foundation for configuration management, ID of WBS ensure the uniqueness. The example of ways WBS as follows, the ID of WBS is the code means type of special work. The code of special work is listed in Tab 1.

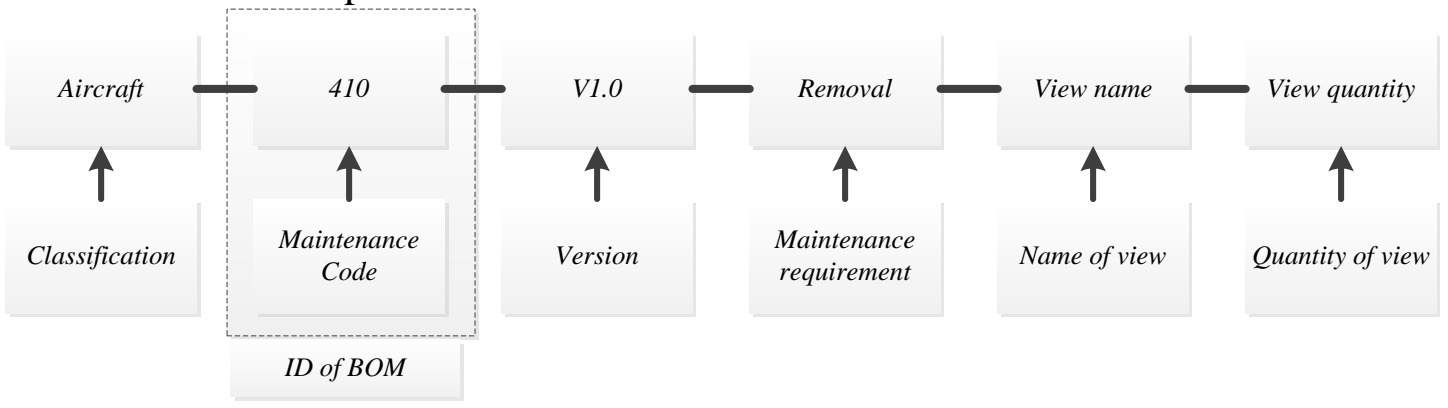

Fig 3 ID of ILS-WBS

Tab 1 Code of special work of WBS- LIS

\begin{tabular}{|c|c|c|}
\hline NO. & Maintenance Code & Maintenance Requirement \\
\hline 1. & 110 & Time Limit \\
\hline 2. & 120 & Maintenance Schedule \\
\hline 3. & 210 & Fuel/Refuel \\
\hline 4. & 310 & Visual Inspection \\
\hline 5. & 320 & On-line Inspection \\
\hline 6. & 410 & Removal \\
\hline 7. & 420 & Installation \\
\hline
\end{tabular}

\subsubsection{Control}

The propose of control of WBS is to centralized in the control of the content and version. On the one hand, the contents of WBS would be based on the requirement of equipment which could adjusted as require, on the other hand, content of WBS would be refine based on previous work.

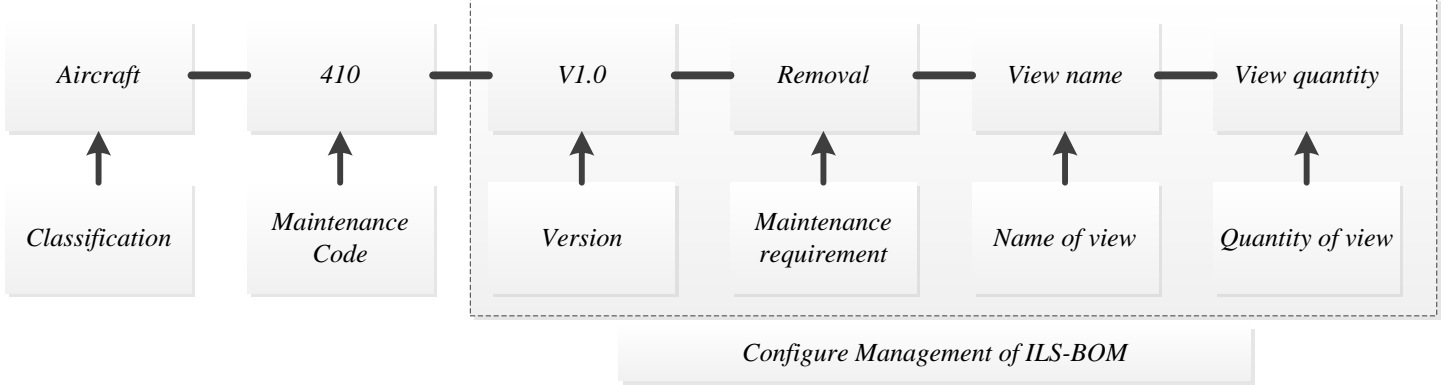

Fig 4 Configure Management of WBS- ILS

\subsubsection{Recording}

The purpose of recording is to realization of traceability of WBS evolution which on the basis of identification and control, and the change of contents and versions could trace the effective by control of WBS.

\section{Confirm to Major Operation}

\subsection{Foundation}

In order to ensure the protection of information systems and equipment to fully support a variety of security work, to ensure that there is neither lack of job item and also to keep individual feather to avoid repeat, it is necessary to integrate WBS and as the core of preparation in equipment Support information System. For example, information systems of one kind of transport as follows. 
First, assume idealized aircraft $\mathrm{A}$, its requirement of maintenance covers all current specific project, WBS of A as follow.

$G_{A}=\left\{P_{1}, P_{2} \ldots P_{N}\right\}, N$ means all maintenance requirement.

Secondly, set $\alpha$ as one kind of aircraft, the WBS as follow:

$G_{\alpha}=\left\{P_{1}, P_{2} \ldots P_{\alpha}\right\}, \alpha \subset N$

Set $\beta$ as one kind of aircraft, the WBS as follow:

$G_{\beta}=\left\{P_{1}, P_{2} \ldots P_{\beta}\right\}, \beta \subset N$

Since $\alpha \subset N$, and $\beta \subset N$, and $\alpha \neq \beta$ 。

Thirdly, to keep the informational system suit to the $\alpha$, but do not suit for $\beta$, and Set

$$
f_{d i}=\left\{\begin{array}{l}
1, \text { suit } \\
0, \text { no }
\end{array}\right. \text { as the decide function }
$$

\subsection{Example}

To set up business function of support informational system, the key point is to keep with the identical requirement. The identical requirement depends on the WBS which based on analysis the equipment special and the relationship with resource of logistic.

For example, set one kind of transport $\mathrm{S}$ as informational system in business functions setting as follows.

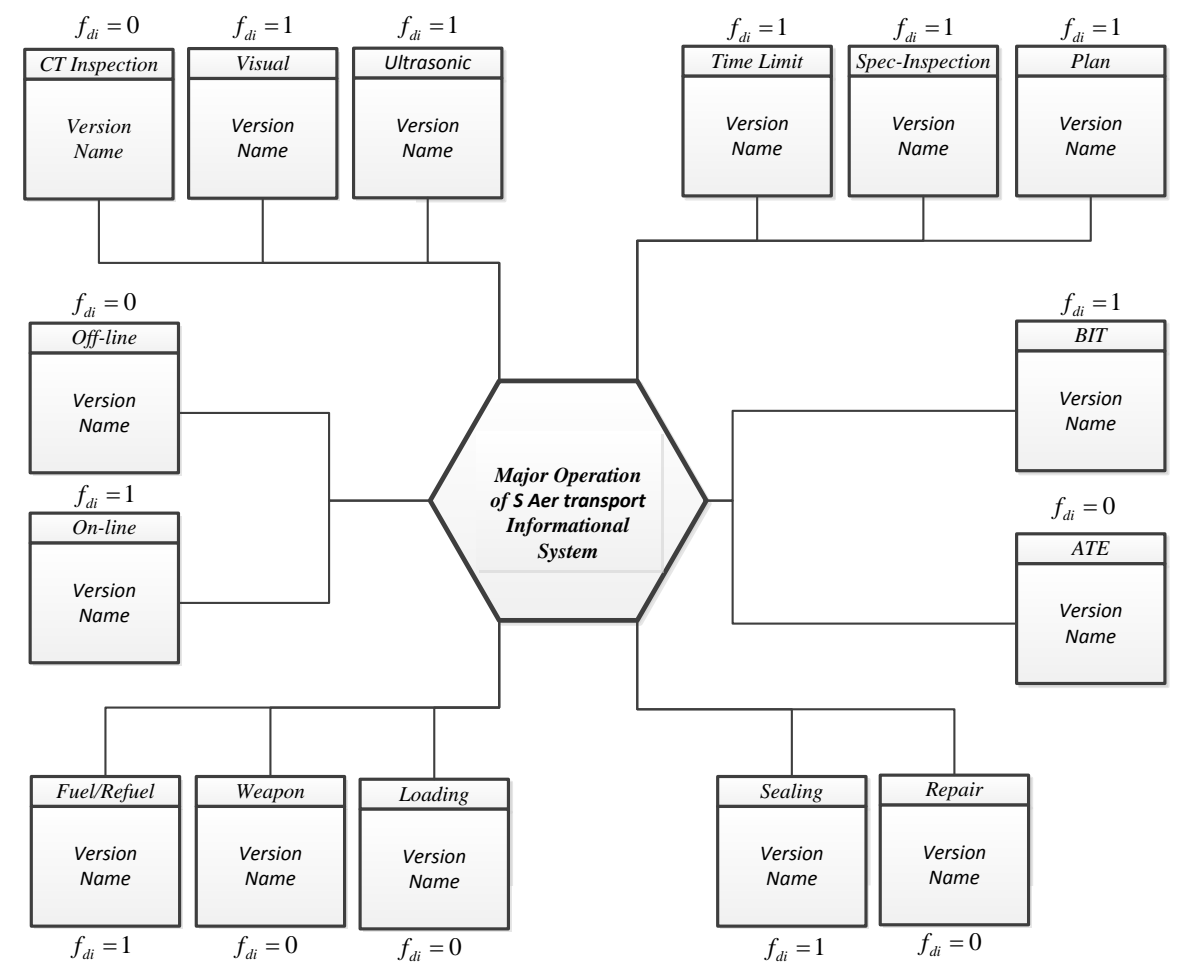

Fig 5 Major Operation of Informational System for S Aero transport

Above all, the business functional setting is as follow.

Tab 2 Business Function of $S$ Transport

\begin{tabular}{|c|c|}
\hline NO. & Business Function \\
\hline 1 & Visual Inspection \\
\hline 2 & Ultrasonic Inspection \\
\hline 3 & Time Limit \\
\hline 4 & Spec-inspection \\
\hline 5 & Plan \\
\hline 6 & BIT \\
\hline 7 & Sealing \\
\hline 8 & Fuel/Refuel \\
\hline 9 & On-line Inspection \\
\hline
\end{tabular}




\section{Conclusion}

1.The method to confirm the informational systems business function has been established.

As the support resources is the necessary feather for all kinds of equipment, this research build up relationship between support resources and special work to confirm the business functional setting. To acquire the special work of each kind of equipment, the WBS of logistics has been introduces as method to overcome the difficult. For regular WBS, the configuration management of method was completed. Above all, the method to confirm the informational systems business function through WBS would both provide proof to establish business function of equipment support informational system and keep the feather of identical requirement.

\section{References}

[1]Lan-Zhi, Ma-Haodong, Yu-Gongjing. Study of Information-based Weapon Equipment Maintaining and Assistant Decision-making Technology[J]. Computer Measurement \& Control. 2006.14 (12):1670-1672.

[2]ZHANG-Wei, LI-Zhongmeng. Discussion about Support Ways of Equipment under Information War[J]. 2012.32(1):12-13.

[3]WANG-chaoyang. Research of Weapon \& Equipment Logistic Support in Informational Warfare[D].PLA University of Information Engineering.2006.

[4]CUI-xiaojie, YANG-jun, SU-jingjing, etc. Data Arrangementof Equipment Maintenance Support Information [J].Journal of SICHUAN Industry and Technology. 2008.29(6):125-127.

[5]WANG-pingcai. Research on BOM management and implementation of PDM Based on Technology [D] Huazhong University of Science and Technology.2006

[6]HUANG-qing. Research on Product Family Configuration Design and Optimization Method Based on Modular Product Family Master Structure[D].TIANJIN University.2013

[7]JIANG-peipei. Research and Application of the Order Allocation Function [D]. Shanghai Jiaotong University .2011

[8]CHEN-yan, SHAN-quan. Research on Family Product Model[J].Design \& Research.2009,4:11-14.

[9]QIN-honghbin. Research on Design Technology product family based on common product platform[D]. Huazhong University of Science and Technology.2006

[10] W.Y.Zhang, S.Y.Tor. Managing modularity in product family design with functional modeling[J]. Journal of Advanced ManufacturingTechnology.2006,30:579-588

[11] Jiao J. and M.M.Tseng. Understanding product family for mass customization by developing commonality indices[J]. Journal of Engineering Design.2000.11

[12] Xuehong Du. Architecture of product family for mass customization[J]. Management of Innovation and Technology.2000.1: 437-443

[13]SHE-xiaohua, Research on the construction and configuration of the general work breakdown structure model based on K-MEDOIDS[D].HUNAN university,2011.

[14]XU-yihua, Technical State Management In Information System Development[J].Informational Technology \&Standard.2014(6):37-39. 